\title{
Different Roles for Simple-Cell and Complex-Cell Inhibition in $\mathrm{V} 1$
}

\author{
Thomas Z. Lauritzen ${ }^{1,4}$ and Kenneth D. Miller ${ }^{1,2,3,4}$ \\ ${ }^{1}$ Graduate Group in Biophysics, ${ }^{2}$ Departments of Physiology and Otolaryngology, ${ }^{3}$ Sloan-Swartz Center for Theoretical Neurobiology, and ${ }^{4}$ W. M. Keck \\ Center for Integrative Neuroscience, University of California, San Francisco, California 94143-0444
}

\begin{abstract}
Previously, we proposed a model of the circuitry underlying simple-cell responses in cat primary visual cortex (V1) layer 4. We argued that the ordered arrangement of lateral geniculate nucleus inputs to a simple cell must be supplemented by a component of feedforward inhibition that is untuned for orientation and responds to high temporal frequencies to explain the sharp contrast-invariant orientation tuning and low-pass temporal frequency tuning of simple cells. The temporal tuning also requires a significant NMDA component in geniculocortical synapses. Recent experiments have revealed cat V1 layer 4 inhibitory neurons with two distinct types of receptive fields (RFs): complex RFs with mixed ON/OFF responses lacking in orientation tuning, and simple RFs with normal, sharp-orientation tuning (although, some respond to all orientations). We show that complex inhibitory neurons can provide the inhibition needed to explain simple-cell response properties. Given this complex cell inhibition, antiphase or "push-pull" inhibition from tuned simple inhibitory neurons acts to sharpen spatial frequency tuning, lower responses to low temporal frequency stimuli, and increase the stability of cortical activity.
\end{abstract}

Key words: visual cortex; contrast invariance; orientation tuning; simple cell; complex cell; V1; inhibition; push-pull; stability

\section{Introduction}

Understanding the circuitry underlying response properties in primary visual cortex (V1) remains a central problem in systems neuroscience (Ferster and Miller, 2000) and serves as a model problem for understanding cortical processing. Hubel and Wiesel (1962) proposed that the orientation selectivity of simple cells in cat V1 layer 4 is shaped by an oriented arrangement of input from cells in the lateral geniculate nucleus (LGN) that are not tuned for orientation. Such an input pattern has been verified experimentally (Tanaka, 1983; Reid and Alonso, 1995; Alonso et al., 2001) but is not sufficient to explain simple-cell response properties. In response to a drifting grating stimulus, the mean LGN input to a simple cell grows with increasing contrast for all orientations, so that the mean input evoked by nonpreferred orientations at high contrast exceeds the peak input evoked by the preferred orientation at low contrast (Troyer et al., 1998). Yet, orientation-tuning bandwidth remains approximately constant across contrasts, a phenomenon known as contrast-invariant orientation tuning (Sclar and Freeman, 1982; Skottun et al., 1987; Anderson et al., 2000b). Similarly, in response to a high temporal frequency drifting grating $(\geq 20 \mathrm{~Hz})$ that produces little or no response in the great majority of V1 cells (Ikeda and Wright, 1975; Movshon et al., 1978; Holub and Morton-Gibson, 1981; Saul and Humphrey, 1992b; DeAngelis et al., 1993; Freeman et

\footnotetext{
Received May 27, 2003; revised Sept. 10, 2003; accepted Sept. 12, 2003.

This work was supported in part by a predoctoral fellowship from the Danish Research Agency (T.Z.L.) and National Eye Institute Grant R01-EY11001.

Correspondence should be addressed to Kenneth D. Miller, Department of Physiology, University of California 513 Parnassus, San Francisco, CA 94143-0444. E-mail: ken@phy.ucsf.edu.

Copyright $\odot 2003$ Society for Neuroscience $\quad$ 0270-6474/03/2310201-13\$15.00/0
}

al., 2002), the great majority of LGN cells fire strongly (at levels greater than half their response to their optimal temporal frequency) (Freeman et al., 2002). Thus, a high-contrast, optimally oriented $20 \mathrm{~Hz}$ grating should evoke a high mean rate of LGN input to a simple cell (even if mechanisms that act as low-pass filters remove the temporal modulation of the input) that exceeds the peak LGN input in response to a sufficiently low-contrast grating of optimal temporal frequency and orientation. Yet, almost all simple cells respond to the optimal low-contrast stimulus and not to the $20 \mathrm{~Hz}$ high-contrast stimulus.

We suggested previously a model of cat V1 layer 4 that can account for the contrast-invariant orientation tuning (Troyer et al., 1998), temporal frequency tuning (Krukowski and Miller, 2001), and other response properties (Kayser et al., 2001; Lauritzen et al., 2001) of simple cells. The essential idea is that strong feedforward inhibition (inhibition from cortical interneurons driven by LGN inputs) that shows contrast-dependent responses to all orientations and to all temporal frequencies that drive LGN cells supplements feedforward excitation from LGN inputs to account for simple-cell response properties. Given that most layer 4 cells are simple (Gilbert, 1977; Bullier and Henry, 1979) and given one report of a simple layer 4 inhibitory neuron (Gilbert and Wiesel, 1979), we assumed that the inhibitory neurons providing this inhibition would be simple cells. The inhibition and excitation received by a layer 4 simple cell have similar orientation tuning (Ferster, 1986; Anderson et al., 2000a; Martinez et al., 2002) but are arranged in a spatially opponent or "pushpull” relationship; in ON subregions, light evokes excitation and dark evokes inhibition, and vice versa in OFF subregions (Ferster, 1988; Hirsch et al., 1998; Anderson et al., 2000a). Therefore, our model was based on antiphase inhibitory connectivity: an inhib- 
itory simple cell tended to connect to cells that preferred dark where it preferred light, and vice versa. These inhibitory simple cells were predicted to respond to all orientations in a contrastdependent manner, although showing a tuned peak of response, and to show temporal frequency tuning like that of LGN cells.

Results of intracellular in vivo recording of cells that were subsequently filled and reconstructed were reported recently (Hirsch et al., 2000, 2003). A total of 10 anatomically identified inhibitory neurons in cat V1 layer 4 have been recorded. Four had complex of receptive fields (RFs) with mixed ON/OFF responses throughout the responsive region. These cells showed approximately equal responses to all orientations with little (two cells) or no (two cells) sign of orientation bias. The other six had simple RFs: segregated, oriented ON and OFF subregions with push-pull inhibition. These cells were well tuned for orientation in response to high-contrast drifting bars, although two showed a substantial response to all orientations. Reexamination of previous studies supports the finding that a substantial fraction of cat V1 layer 4 interneurons are complex cells; of nine previously anatomically identified such neurons, five were simple and three were complex (one was unoriented center-surround) (Gilbert and Wiesel, 1979; Martin et al., 1983; Kisvarday et al., 1985; Gabbott et al., 1988; Ahmed et al., 1997). The orientation tuning of these complex cells was not discussed. In addition, Azouz et al. (1997) anatomically identified one layer 4 interneuron, which was orientation untuned, although its complex or simple nature was not discussed. These results suggest that the broadly tuned inhibition that we posited indeed exists but primarily in the form of orientation-untuned complex, rather than simple inhibitory neurons.

In this study, we explore the hypothesis that complex inhibitory neurons lacking in orientation tuning and hypothesized to have temporal tuning that follows that of their LGN inputs, provide the inhibition that explains the contrast-invariant orientation tuning and temporal frequency tuning of simple cells. We also explore the role in this scenario of antiphase inhibition provided by the sharply tuned simple inhibitory cells. An abstract of this work has been reported previously (Lauritzen and Miller, 2002).

\section{Materials and Methods}

The model we study is similar to a model described previously ["computational model" of Troyer et al. (1998)], with the major differences: (1) that we have included two types of inhibitory cells, simple inhibitory cells and the complex inhibitory cells recently described by Hirsch et al. (2000, 2003), and (2) that we have included NMDA as well as AMPA receptors in excitatory synapses, as described by Krukowski and Miller (2001) but with a different $\mathrm{Mg}^{2+}$ concentration. The detailed methods are as in Troyer et al. (1998), except where otherwise described. Here, we present the basics of the model along with the present additions.

Model input. The input to our model comes from 7200 LGN X-cells arranged in four overlying $30 \times 30$ sheets of $\mathrm{ON}$ cells and four similar sheets of OFF cells, with ON and OFF lattices offset by one-half squarelattice spacing covering $6.8 \times 6.8^{\circ}$ of the visual field. We used four overlying sheets because we assumed each LGN X-cell received input from a single retinal ganglion (RG) X-cell, and each RG X-cell projected to four LGN X-cells (as in Wörgötter and Koch, 1991) [this value is intermediate between values reported by Sherman (1985) and Peters and Yilmaz (1993)].

LGN firing rates, in response to a drifting grating, were calculated by assuming rates were sinusoidally modulated up to rectification at zero rate about background rates of 10 and $15 \mathrm{~Hz}$ for ON and OFF cells, respectively. The amplitude of the sinusoidal modulation was chosen so that the first harmonic (F1) of the rectified responses matched experimental values from one published X-cell (Sclar, 1987, Fig. 1). These LGN data are used in most of our later studies (Kayser et al., 2001; Krukowski and Miller, 2001; Lauritzen et al., 2001; Troyer et al., 2002) but not in our original study (Troyer et al., 1998); these data are used because they are the only published data of which we are aware that includes responses both at multiple temporal frequencies and multiple contrasts. This LGN cell has a high-contrast temporal frequency tuning curve (essentially identical to the curve illustrated in Fig. $6 b$ ) that peaks at $16 \mathrm{~Hz}$, which is on the high end for LGN X-cells (Derrington and Fuchs, 1979; Lehmkuhle et al., 1980; Sclar, 1987; Saul and Humphrey, 1990; Hamamoto et al., 1994). However, its overall range of temporal tuning is more typical (e.g., the average tuning; over all X-cells shows a broad peak extending from 4 to $16 \mathrm{~Hz}$ with responses still above half-maximal at $32 \mathrm{~Hz}$ ) (Sclar, 1987, Fig $5 C$ ), and almost all LGN cells respond with more than one-half of their maximal response to stimuli of $\geq 20 \mathrm{~Hz}$ (Freeman et al., 2002; but see Lehmkuhle et al., 1980, and Saul and Humphrey, 1990, who found lower LGN cutoffs). The data from the Sclar study determined the amplitude as a function of temporal frequency and contrast. This amplitude was then scaled by a factor reflecting the spatial frequency of the grating, given by the spatial frequency transfer function computed from the spatial receptive field of LGN cells as provided by Troyer et al. (1998), with the transfer function scaled so that its peak value is 1 . Spikes were then generated from these LGN firing rates in a random (Poisson) manner. Overlying LGN cells have 25\% correlation in their spike trains, matching data showing correlation among LGN cells with overlapping RFs (Alonso et al., 1996).

Model architecture. The model consists of a grid of $40 \times 40$ excitatory simple cells (E) and two grids of $15 \times 15$ inhibitory cells, one of simple cells $\left(I_{\mathrm{s}}\right)$ and one of complex cells $\left(I_{\mathrm{c}}\right)$ (Hirsch et al., 2000, 2003). All cells represent layer 4 cells, representing a two-third $\times$ two-third millimeter patch of cortex corresponding to $0.75 \times 0.75^{\circ}$ in visual angle.

Each simple cortical cell was assigned a Gabor function describing its $\mathrm{RF}$, with orientation given by a measured orientation map from cat V1, spatial frequency of 0.8 cycles per degree, retinotopic position progressing uniformly across the sheet, and spatial phase assigned randomly to each cell. The precise parameters used for the Gabor functions were those specifying the "broadly tuned" cells of Troyer et al. (1998), reproducing the observed (Ferster et al., 1996; Anderson et al. 2000a) $35^{\circ}$ half-width at half-height $(\mathrm{HWHH})$ of the orientation tuning of intracellular voltage modulations in response to optimal sinusoidal gratings. The connection strength from LGN cells to a cortical simple cell was determined, as in Troyer et al. (1998), by a probabilistic sampling of the Gabor function of the cell, in which positive regions of the Gabor are converted to probabilities of a connection from an ON cell centered on that point and negative regions converted to probabilities of OFF cells connecting.

The complex cell RFs were constructed to have dimensions comparable with the simple cells, but round, by giving them a Gabor envelope with a diameter equal to the geometric mean of the length and width of the simple cells. The LGN connections were determined with the same algorithm as for the simple cells with the difference that a random number was assigned as the phase for each possible connection. That is, a Gabor RF with the preferred orientation given by the orientation map was assumed, but the phase of this RF was chosen randomly for each possible LGN connection to determine the probability of that connection. This caused the cell to receive input from both LGN ON and OFF cells at any given retinotopic point, resulting in mixed ON-OFF RFs untuned for orientation, but overall to receive the same amount of LGN input as the simple cells.

Cortical cells were modeled as single-compartment conductancebased integrate-and-fire neurons as in the Troyer et al. (1998) study, and the two types of inhibitory cells had the same biophysical parameters. Each cell received stimulus-independent background excitatory input (Poisson) at a rate of $4000 \mathrm{~Hz}$. This, along with the spontaneous activity of the LGN inputs, resulted in background firing rates of $\sim 0.7 \mathrm{~Hz}$ for excitatory cells, $1-2 \mathrm{~Hz}$ for simple inhibitory cells, and $30-40 \mathrm{~Hz}$ for complex inhibitory cells. The spontaneous rate for complex cells is somewhat high but comparable with rates of $\sim 20 \mathrm{~Hz}$ reported for similarly nonspecific inhibitory interneurons in other areas of the cortex (Simons and Carvell, 1989; Swadlow, 1989, 1990, 1991, 1994; Brumberg et al., 1996). The rates could be decreased without substantial changes in over- 
all model behavior by decreasing the background inputs to complex cells (we kept these identical to all cortical cells for simplicity) or by including inhibitory chemical synapses between complex cells (Tamas et al., 1997, 1998; Gibson et al., 1999; Galarreta and Hestrin, 2002) or lowering the strength of LGN inputs to complex cells (we kept the strengths of LGN inputs identical on all cortical cells for simplicity). These could be compensated by increasing the synaptic strengths of connections from complex cells, but we have not explored any of these steps.

NMDA-mediated conductances (Krukowski and Miller, 2001; Lauritzen et al., 2001), in addition to the AMPA-mediated conductances, were added to all excitatory synapses, except for the thalamocortical synapses onto inhibitory cells, which were purely AMPA mediated, after evidence that there was little NMDA in excitatory synapses onto inhibitory cells (Ling and Benardo, 1995; Angulo et al., 1999). The relative strength of NMDA and AMPA conductances was set in terms of the integrated current (i.e., the total charge transfer) through excitatory conductances when the postsynaptic cell was clamped at the spike-threshold voltage. Seventy-five percent of the integrated current in all synapses was mediated by NMDA, which is the value obtained by matching AMPA and NMDA amplitudes to those observed at thalamocortical synapses at the oldest ages studied in thalamocortical slices (Crair and Malenka, 1995), using a physiological level of extracellular $\mathrm{Mg}^{2+}$. NMDA was modeled as in the study by Krukowski and Miller (2001), except that $\mathrm{Mg}^{2+}$ concentration of $1.3 \mathrm{~mm}$ rather than $100 \mu \mathrm{M}$ was used. The latter figure was an error and led us to conclude that $>90 \%$, rather than $75 \%$, of integrated current was carried by NMDA.

The probability of forming a synapse between any pair of simple cells depended on the correlation between their sets of LGN inputs, as described by Troyer et al. (1998). The probability of a connection from an excitatory cell monotonically increased with the degree of correlation, whereas the probability of a connection from an inhibitory cell monotonically increased with the degree of anticorrelation. As shown in Troyer et al. (1998) (see Fig. 8 B), the result is that the distribution of orientation differences between connected cell pairs peaks at zero difference and falls to zero at differences of approximately $\pm 30^{\circ}$, whereas the distribution of phase differences peaks at zero difference for excitatory synapses and at $180^{\circ}$ for inhibitory synapses, and falls to zero over approximately $\pm 60^{\circ}$ from the peak. The result of this connectivity pattern is that the excitatory currents and inhibitory currents received by a cell in response to preferred orientation drifting gratings modulate approximately at opposite phases across spatial (see Fig. $4 b$ ) and temporal frequencies (Krukowski and Miller, 2001, their Fig. 1B,C).

Connections from complex cells only depend on the distance between the receptive fields of the two cells, with $10 \%$ probability of forming a synapse onto cells less than $150 \mu \mathrm{m}$ away and zero otherwise. For simplicity, complex cells only receive thalamocortical input. These connectivity rules yield the basic cortical circuit structure within a single isoorientation column shown in cartoon form in Figure 1a. An important feature of the model is that the inhibition is dominant over feedforward excitation, rather than precisely balancing it.

The thalamocortical and $\mathrm{E} \rightarrow \mathrm{E}$ synapses displayed depression, with $f=$ $0.563, \tau=99 \mathrm{msec}(\mathrm{LGN})$, and $f=0.875, \tau=57 \mathrm{msec}(\mathrm{E} \rightarrow \mathrm{E})$. Here, $f$ is the synaptic efficacy immediately after a presynaptic spike, and $\tau$ is the time constant of recovery, as in Abbott et al. (1997). The experimental basis for these depression parameters is discussed in Table 1 of Kayser et al. (2001). Connections onto and from inhibitory cells may also express use-dependent changes (Gupta et al., 2000), but these have been omitted for simplicity.

As described previously (Troyer et al., 1998), we defined the total synaptic strength of a given type received by a cell by the following: (1) assuming the cell is voltage clamped at threshold; (2) over time, for each synapse, integrating the synaptic current induced by one presynaptic spike; and (3) summing over all synapses of the given type. Thus, total synaptic strength is expressed as nA msec. For simulations using only simple-cell inhibition, $I_{\mathrm{s}} \rightarrow I_{\mathrm{s}}$ connections were set to zero, because $I_{\mathrm{s}} \rightarrow I_{\mathrm{s}}$ connections can create instability in such a network unless they are very weak (Krukowski, 2000). The remaining connection strengths were 20 $(\mathrm{LGN}), 5(\mathrm{E} \rightarrow \mathrm{E})$, and $5 \mathrm{nA} \mathrm{msec}\left(I_{\mathrm{s}} \rightarrow \mathrm{E}\right)$, as used previously for networks containing only simple-cell inhibition with the synaptic depression pa- rameters used here (Krukowski, 2000). When a mixture of complex- and simple-cell inhibition was included, the total synaptic weight received by a cell from each type of connection was: $25(\mathrm{LGN}), 4\left(I_{\mathrm{c}} \rightarrow \mathrm{E}\right), 10\left(I_{\mathrm{c}} \rightarrow I_{\mathrm{s}}\right)$, $8.5\left(\mathrm{E} \rightarrow \mathrm{E}, I_{\mathrm{s}}\right)$, and $8 \mathrm{nA} \operatorname{msec}\left(I_{\mathrm{s}} \rightarrow \mathrm{E}, I_{\mathrm{s}}\right)$. For simulations using only complex-cell inhibition, strengths were identical to these, except that all connections from $I_{\mathrm{s}}$ cells were set to zero. These strengths were set empirically in a stepwise manner. First, LGN strengths were set to yield discernible orientation tuning of the firing rate of the excitatory cortical cells at the lowest contrast $(2.5 \%$ contrast $)$ in a network without intracortical connections. This strength was sufficient for a network with only simple cell inhibition, in which inhibition is withdrawn at the optimal orientation and phase, but it needed to be increased to obtain robust tuning that overcame noise fluctuations in a network with complex cell inhibition. In an iterative process, LGN strengths were set to the minimum values that allowed this, whereas $I_{\mathrm{c}} \rightarrow \mathrm{E}$ connections were set to give reasonably sharp orientation tuning of $\mathrm{E}$ cells without too much dampening of preferred responses. Once this was achieved, E $\rightarrow$ E connections were set to give reasonable overall spike rates to a preferred stimulus, and $\mathrm{E} \rightarrow I_{\mathrm{s}}$ connections were set equal for simplicity; then, $I_{\mathrm{c}} \rightarrow$ $I_{\mathrm{s}}$ connections were increased to yield sharp orientation tuning of $I_{\mathrm{s}}$ cells; finally, connections from $I_{s}$ cells were set to give a reasonable inhibitory current modulation in E-cell responses and were set equal onto $\mathrm{E}$ and $\mathrm{I}_{\mathrm{s}}$ cells for simplicity. In simulations of Figure 7, as indicated in Results, all intracortical synaptic strengths from $I_{c}$ and E cells were increased by $20 \%$; synaptic strengths from LGN and, when present, from $I_{s}$ remained at default levels.

Each simulation started with a blank screen for $1 \mathrm{sec}$, with LGN cells firing at their background rates to equilibrate the network, followed by an additional $0.25 \mathrm{sec}$ with a grating stimulus to suppress transients before actually recording data for $1 \mathrm{sec}$ of simulated time as the grating stimulus continued. For all figures, except Figures 2 and 3 , simulations were run at $40 \%$ contrast with a grating oriented at $128^{\circ}$ to avoid artifacts of the grid with the stimulus. Tuning curves were calculated from 20 such simulations (with different random seeds for the Poisson spike trains of the LGN inputs) and from responses of all cells with preferred orientations within \pm 5 of $128^{\circ}$. To determine orientation tuning curves (Figs. 2, 3), responses were obtained from gratings having each of 18 orientations from $8-178^{\circ} \times 10^{\circ}$ at each of the indicated contrasts, using one repetition of each grating. Cells were binned by preferred orientation in bins of $\pm 5^{\circ}$ around each grating orientation. The tuning curve of each bin was determined, and tuning curves of different bins were averaged together by equating the central orientation of each bin (representing orientation $0^{\circ}$ in Fig. 2).

Toy model. To assess the stabilizing effect of the push-pull inhibition, we constructed a simple model consisting only of current input to a simple cell. The firing rate of the cell is $r(t)=\left[I_{f f}(t)+I_{e x}(t)-I_{c}-I_{s}(t)-\right.$ $\theta]^{+}$, with $I_{f f}(t)=[\sin (t)]^{+}$as the thalamocortical input current, $I_{e x}(t)=$ $r(t) \times w_{e x}$ as the excitatory recurrent input current, $I_{c}=C$ as the constant complex cell inhibitory current, and $I_{s}(t)=\left[w_{s} \times \sin (t+\pi)\right]^{+}$as the simple inhibitory cell push-pull current $(t$, time in cycles; $\theta$, firing threshold; $w_{e x}$, recurrent excitatory input strength; $w_{s}$, simple inhibitory cell input strength). $[x]^{+}=x$ if $x>0$, and 0 otherwise. In the presented simulations, we vary $C$ and $w_{e x}$ and fix $w_{s}=15, \theta=0$. Changing $w_{s}$ varies the stable regime for simple-cell inhibition, and increasing $\theta$ has the same effect as increasing $I_{c}$. The value $w_{s}=15$ was chosen to make excitatory and inhibitory currents of approximately equal amplitude in Figure $8 b$. Any value of $w_{s}>0$ increases the stable area (see Fig. $8 c$ ), with a greater increase in area for larger $w_{s}$.

Computing the effect of variability in integration times. In the Discussion, we state an approximate estimate of the effects of variability of LGN integration times (Saul and Humphrey, 1990; Mukherjee and Kaplan, 1995) on the amplitude of temporal modulation of the LGN input to a simple cell, which is obtained as follows. We considered the change in amplitude from 2 to $8 \mathrm{~Hz}$ drifting grating stimulation. To simplify, we assumed that all of the inputs of the cell are perfectly in phase at $2 \mathrm{~Hz}$, and that their integration times are uniformly distributed between $-\tau$ and $\tau$ about some central value. As a conservative assumption, we used $\tau$ to cover the full range of experimentally observed integration times, although an individual simple cell receives LGN inputs with correlated 
temporal response properties (Alonso et al., 2001). Then, at $8 \mathrm{~Hz}$, the phases will be uniformly distributed between $-\phi$ and $\phi$, where $\phi=2 \pi \tau$ $(6 \mathrm{~Hz})$ in radians. The sum of the inputs at their peak at $8 \mathrm{~Hz}$, ignoring the effects of temporal integration for simplicity, is then proportional to $\int_{-\phi}^{\phi}$ $d \theta \cos (\theta)=2 \sin (\phi)$, whereas the sum at $2 \mathrm{~Hz}$ is proportional to $\int_{-\phi}^{\phi} d \theta$ $\cos (0)=2 \phi$. Thus, the ratio of $8 \mathrm{~Hz}$ peak modulation amplitude to $2 \mathrm{~Hz}$ peak modulation amplitude is $r=\sin (\phi) / \phi$.

To apply this result, we considered a simple cell receiving only input from nonlagged $\mathrm{X}$-cells, because this is the only kind of input considered in this study, most cat V1 cells receive primarily or exclusively X-cell input (Ferster, 1990a, b), and the majority have only, or almost only, nonlagged-type timing in their receptive fields (Saul and Humphrey, 1992a). Nonlagged X-cells have a range of integration times spanning $\pm 35 \mathrm{msec}$ (Saul and Humphrey, 1990) or less (Mukherjee and Kaplan, 1995) (setting, $\tau=0.35$ msec yields $r=0.73$ ). Lagged $X$-cells have a broader range of integration times $( \pm 50 \mathrm{msec}$ ) (Saul and Humphrey, 1990 ), yielding $r=0.50$. Cells that receive a mix of nonlagged and lagged input appear to receive them in spatially segregated subregions (Saul and Humphrey, 1992a) and could show greater demodulation resulting from the relative phase shift between nonlagged and lagged inputs, which differ in mean integration time by $70 \mathrm{msec}$ (Saul and Humphrey, 1990). However, such cells are also likely to change their direction selectivity with increasing temporal frequency (Saul and Humphrey, 1992b). Thus, analysis of the modulation to an optimal stimulus with changing temporal frequency becomes more complicated, because the optimal stimulus may change with temporal frequency.

\section{Results}

\section{Model overview}

The model contained the following three cortical cell types found in cat V1 layer 4: orientation-tuned excitatory and inhibitory simple cells with separate $\mathrm{ON}$ and OFF subfields, and inhibitory complex cells untuned for orientation with mixed ON-OFF receptive fields (Hirsch et al., 2000, 2003). All cells received thalamocortical input selected probabilistically, simple cell inputs chosen from ON-center inputs overlying ON subregions and OFF-center inputs overlying OFF subregions (Hubel and Wiesel, 1962; Tanaka, 1983; Reid and Alonso, 1995; Alonso et al., 2001), and complex cell inputs chosen from all LGN cells whose RFs overlap. Cortical connectivity was also determined probabilistically, with the most probable connections illustrated in the cartoon in Figure 1a. The simple cells formed synapses primarily to other cells with similar preferred orientation, according to the correlation of their RFs. Excitatory synapses were formed to cells with correlated RFs (similar preferred orientation and similar absolute spatial phase; meaning that ON subregions of the two cells tended to overlap in visual space and similarly OFF subregions tended to overlap), and inhibitory synapses were formed to cells with anticorrelated RFs (similar preferred orientation and opposite absolute spatial phase; meaning that ON subregions of one cell tended to overlap OFF subregions of the other cell). The complex cells project randomly with equal (10\%) probability to all simple cells within $150 \mu \mathrm{m}$ and, for simplicity, do not receive any cortical input. The model contained simple cells preferring all orientations and all spatial phases and a range of retinotopic positions. In particular, the relative spatial phase (which refers to the locations of $\mathrm{ON}$ and OFF subregions relative to the receptive field center) of each simple cell is assigned randomly. Only receptive fields with even symmetry are illustrated in Figure 1, but these are not favored over other relative spatial phases in the model.

We designed the architecture so that complex inhibitory cells would lack orientation tuning, as observed, and the feedforward inhibition from the complex cells would cause both inhibitory and excitatory simple cells to have sharp orientation tuning with-

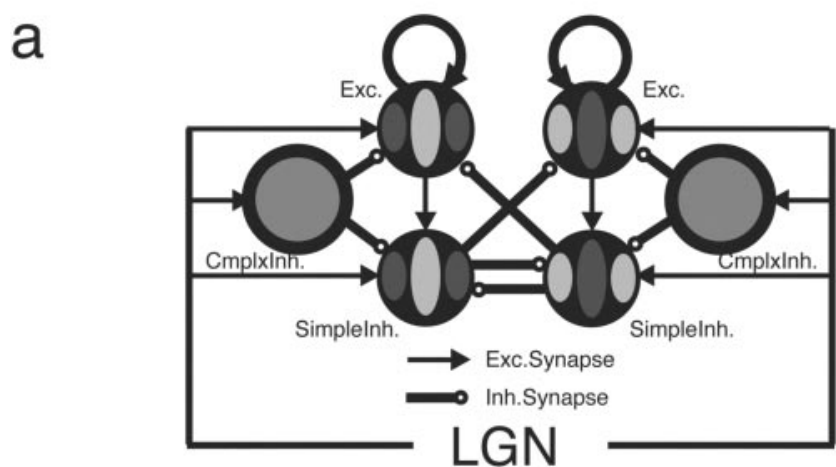

Preferred orientation Orthogonal orientation


Figure 1. Overview of the model and its behavior with different types of inhibition. $a$, Cartoon of model circuit. Top, Two excitatory simple-cell RFs. Bottom, Two inhibitory simple-cell RFs, with ON (light gray) and OFF (dark gray) subregions. Both cell types are tuned for orientation. Middle, ON-OFF complex-cell RFs in medium gray, untuned for orientation. All RFs in the cartoon are centered at the same retinotopic point. Complex cells inhibit all types of simple cells; simple-cell connectivity is correlation based (push-pull), so that excitatory simple cells tend to connect to other simple cells with which they are well correlated, and inhibitory simple cells tend to connect to other simple cells with which they are strongly anticorrelated. The actual model contains cells of all preferred orientations, spatial phases, and multiple retinotopic positions; only cells with even symmetric receptive fields and vertical preferred orientation are shown in the illustration for convenience, but these are not favored over other types of simple cells in the model. Connections are assigned probabilistically with the most probable connections shown in the cartoon. $b-d$, Example synaptic current traces for a single excitatory cell when stimulating with a drifting grating; excitatory input is shown in black, and inhibitory input is shown in gray. Left, Cell preferring the orientation of the grating. Right, Cell preferring the orientation orthogonal to the grating. $b$, Simple-cell inhibition only. At the preferred orientation, inhibitory current modulates with time in antiphase with excitatory current. c, Complexcell inhibition only. Inhibitory current is unmodulated with time. $d$, Both simple-cell and complex-cell inhibition. Inhibitory current at the preferred orientation has an unmodulated part arising from the complex cell inhibition and a part modulated with time arising from the simplecell inhibition. The cell can reach threshold when the excitatory synaptic current is larger than the inhibitory synaptic current; thus, the response at the preferred orientation is similar in all three cases. At the orthogonal orientation, the inhibitory current dominates the excitatory current at all times, and the cell will not fire.

out responses to orientations orthogonal to the preferred. As described in the Introduction, some simple inhibitory cells, although sharply tuned, respond to all orientations (and thus could provide some of the untuned inhibition needed to explain sharp 
orientation tuning of other simple cells). Similarly, some excitatory simple cells in cats respond to all orientations (Azouz et al., 1997). For simplicity, we ignored these facts and assumed that the only orientation-untuned component of inhibition came from complex cells (see Discussion for additional information).

\section{Background: the LGN input to a simple cell}

Before examining the effects of the model circuit, it is useful to review the nature of the LGN input received by a simple cell in response to drifting gratings of various orientations (Troyer et al., 1998, 2002). In response to a preferred orientation grating, the cell receives LGN input that is strongly temporally modulated [see excitatory traces (black lines) in Figure $1, b-d$, left; although, these include intracortical as well as LGN excitation]. This occurs because the preferred orientation grating causes all of the LGN inputs to the simple cell to modulate their firing rates approximately in phase with one another, peaking together and reaching low or zero firing rates together, so that the temporal modulations of the individual LGN inputs add constructively to produce a strongly modulated total LGN input. In response to a gratingoriented orthogonal to the preferred (which we will refer to as the null orientation of the cell), the cell instead receives an approximately constant, temporally unmodulated rate of LGN input (Fig. $1 b-d$, right, excitatory traces). This input is temporally unmodulated because the null-oriented grating drives different LGN inputs to the cell at different times (some are reaching their peak rates when others are at their lowest rates and others are in the middle) and so the temporal modulations of the individual LGN inputs add destructively. Thus, the total LGN input arrives at a constant, temporally unmodulated rate corresponding to the sum of the mean firing rates of all LGN inputs to the cell. This mean rate of total LGN input is the same for gratings of any orientation, because the mean rates of the individual LGN cells are independent of orientation. Thus, gratings of different orientations are distinguished, not by the mean rate of LGN input they elicit but by the temporal modulation of that input, with the strongest temporal modulation elicited by a grating of the preferred orientation of the cell and little or no modulation at the null orientation.

The mean rate of total LGN input to a simple cell grows with stimulus contrast, because the mean rates of the individual LGN cells grow with contrast. This is a nonlinear effect. Because the mean luminance does not change with changes in contrast, the mean response also would not change if LGN responses were linear in the image. It is induced by the fact that LGN firing rates cannot decrease below zero, whereas they can increase to $100 \mathrm{~Hz}$ or higher, which is many times their background level (10-15 Hz) (Kaplan et al., 1987).

Because the mean input grows with contrast for all orientations, even a null-oriented stimulus can elicit a high rate of LGN input at high contrast, even higher than the peak of the temporally modulated input elicited by a preferred orientation grating at sufficiently low contrast. Yet, simple cells show contrastinvariant orientation tuning (Sclar and Freeman, 1982; Skottun et al., 1987; Anderson et al., 2000b), so that they respond to their preferred orientation even at very low contrast and often do not respond to the null orientation even at high contrast. This problem is solved by the feedforward inhibition in our model network.

\section{Orientation tuning}

In simulations using drifting grating stimuli, we can block the inhibition coming from one of the two inhibitory cell types. If we

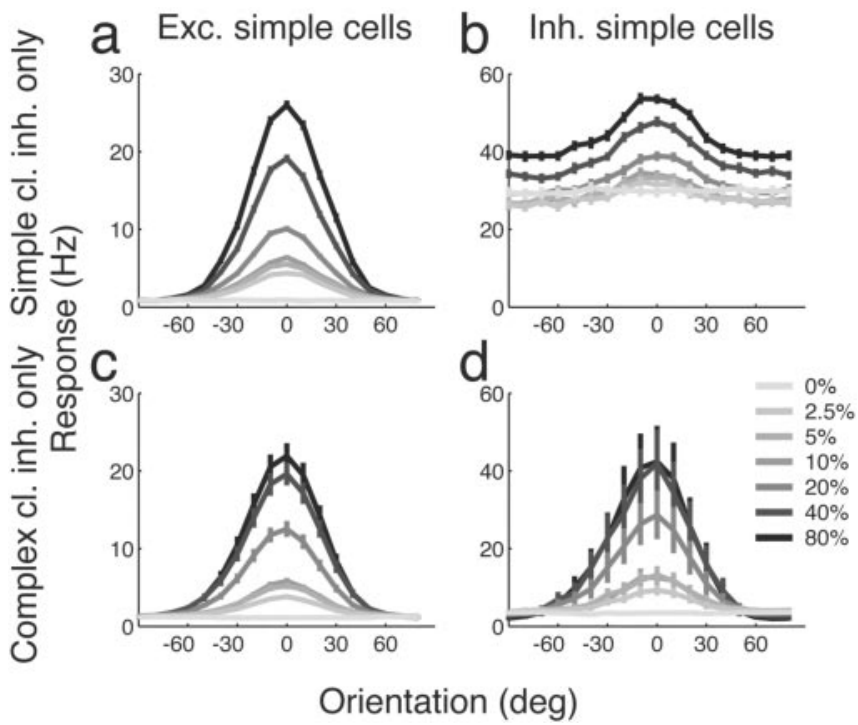

Figure 2. Orientation tuning of cells in the network. $a, b$, Simple-cell inhibition only. $a$, Excitatory simple cells display contrast-invariant orientation tuning. $b$, Inhibitory simple cells have a component tuned for orientation atop a component untuned for orientation; thus, they have a response to all orientations that increases with contrast. $c, d$, Complex-cell inhibition only. Both excitatory $(c)$ and inhibitory $(d)$ simple cells display contrast-invariant orientation tuning. Complex cells are untuned for orientation by design. When both complex-cell and simple-cell inhibition are included, simple cell responses remain as in c and $d$ (data not shown). Error bars in this and subsequent figures are \pm 1 SEM. Here, and in subsequent figures, tuning curves show the mean $(D C)$ response of the cells. Tuning of the F1 of the response is similar in all cases.

block the complex-cell inhibition leaving only simple-cell inhibition, we also must turn off the $I_{s} \rightarrow I_{s}$ connections to avoid instabilities (Krukowski, 2000). (Unless these connections are very weak, they lead to a winner-take-all competition between inhibitory cells of similar preferred orientation and opposite spatial phase. Between inhibitory cells of two such opposite phases, only the one receiving more LGN input at any given time would be active. Orientation tuning in the simple-cell-only model depends on the graded strength of antiphase inhibition; thus, such winner-take-all behavior would greatly broaden the orientation tuning of the excitatory cells.)

In this case, excitatory cells stimulated at their preferred orientation receive excitatory and inhibitory synaptic input currents that modulate out of phase with one another, thus allowing the cells to reach threshold and fire at some point in their cycle (Fig. $1 b$, left). Cells preferring the orthogonal orientation will receive a temporally unmodulated synaptic input from the LGN, regardless of their preferred phase. Thus, an excitatory cell will receive both temporally unmodulated LGN excitation and temporally unmodulated inhibition from inhibitory neurons of similar preferred orientation and approximately opposite absolute spatial phase, which are equally driven by the LGN stimulus. Because the inhibition is dominant, the excitatory cells will not fire (Fig. 1b, right). This yields contrast-invariant orientation tuning for excitatory cells, whereas the inhibitory simple cells, which do not receive inhibition, have responses that mirror the tuning of the LGN input: a response component tuned for orientation atop a component untuned for orientation (Fig. 2a,b). As reported previously (Troyer et al., 1998; Krukowski, 2000), this result holds and responses are stable for a wide parameter regime.

These inhibitory simple cells are primarily simple according to the classical criteria of Hubel and Wiesel (1962), because they 
have spatially segregated $\mathrm{ON}$ and OFF subregions from which their responses can be primarily understood. Furthermore, their responses to a preferred orientation drifting grating have a ratio of first harmonic to mean (F1/DC ratio) $>1$, another standard criterion for simple-cell behavior (Skottun et al., 1991). However, because they do not receive feedforward inhibition to counter the nonlinear nature of their LGN input, they show several nonlinear response characteristics that are not typical of simple cells. Their orientation tuning is not invariant with stimulus contrast (Troyer et al., 1998), and they show a period-doubled response to a counter-phase grating $90^{\circ}$ out of phase with the receptive field of the cell (Wielaard et al., 2001).

If we instead block the simple-cell inhibition (onto both other simple inhibitory cells and simple excitatory cells), leaving only complex-cell inhibition, the inhibitory synaptic current from the complex cells into the excitatory simple cells at the preferred orientation is temporally unmodulated. Because the excitatory synaptic current is temporally modulated, the membrane potential is still able to periodically reach threshold, so the cell will respond (Fig. 1c, left). For cells preferring the orthogonal orientation, both synaptic currents are unmodulated, so that the dominant inhibition prevents responses (Fig. $1 c$, right). The only difference from the previous case (Fig. $1 b$, right) is that the inhibitory synaptic current is now coming from the complex inhibitory cells rather than the simple inhibitory cells. The inhibitory simple cells receive the same type of input, both excitatory and inhibitory, as the excitatory simple cells, so both types of simple cells now display contrast-invariant orientation tuning (Fig. 2c,d).

If both types of inhibition are used, there is an extra contribution of temporally modulated inhibitory synaptic current at the preferred orientation (Fig. 1d, left). This extra current is antiphase with the excitatory synaptic current at the preferred orientation and goes away at nonpreferred orientations (because the inhibitory simple cells do not respond at these orientations) (Fig. $2 d$ ), and thus does not affect the orientation-tuning curves, which remain the same as in Figure 2, $c$ and $d$ (data not shown).

Achievement of sharp, contrast-invariant, orientation-tuned responses via complex-cell inhibition requires relatively tight tuning of inhibitory strength (Fig. 3). If the complex-cell inhibition is too weak, responses at nonpreferred orientations are not suppressed and orientation tuning becomes very wide (Fig. 3, black line). If the complex-cell inhibition is too strong, responses at preferred orientations are suppressed. Thus, overall responses become very weak (Fig. 3, gray line), and contrast invariance of tuning is lost at low contrasts. Only a relatively narrow range of complex-cell inhibitory strengths approximately the value of 4 $\mathrm{nA}$ msec used in our simulations achieves sharp contrastinvariant tuning with realistic response levels. This is quite different from the case in which inhibition comes only from simple cells. In that case, because simple-cell inhibition is antiphase to excitation, even very strong inhibition does not interfere with preferred-orientation responses; thus, a wide range of inhibitory strengths gives realistic responses (Troyer et al., 1998). Physiologically, homeostatic mechanisms (Turrigiano and Nelson, 2000) can adjust the overall level of inhibition (and excitation) of a cell to keep its firing rate within a reasonable range. Such mechanisms may provide the relatively fine tuning of overall inhibitory strength required by complex-cell inhibition.

\section{Spatial frequency tuning}

Given complex-cell inhibition, what role does simple-cell inhibition play? For simple-cell inhibition to play a role in shaping the

\section{Exc. cell responses}

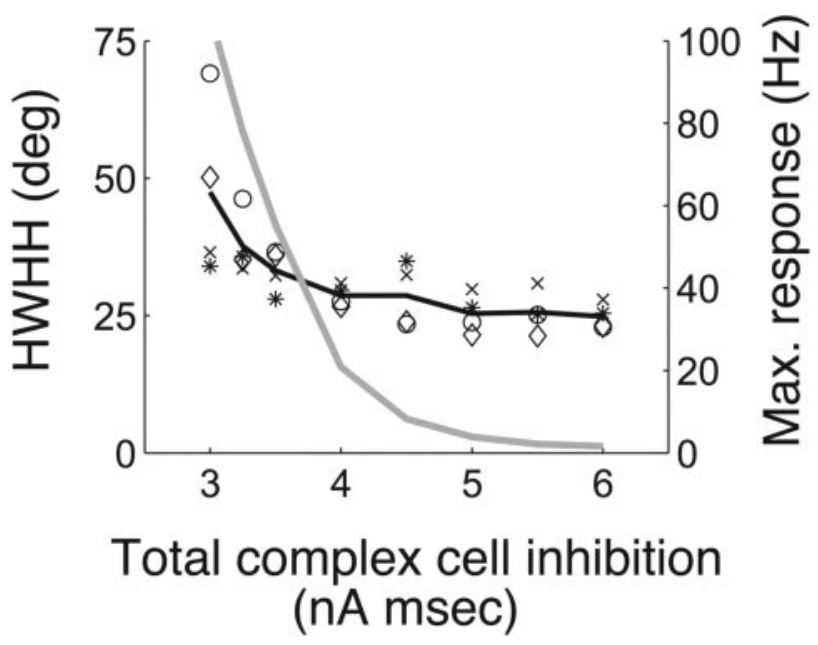

Figure 3. Tuning of the excitatory cell responses as a function of complex cell inhibition for constant excitatory strength and no simple cell inhibition. The left axis and black curve show half-width at half-height of the orientation tuning curve $\left({ }^{*}, 10 \%\right.$ contrast; $\times, 20 \%$ contrast; $\bigcirc$, $40 \%$ contrast; $\diamond, 80 \%$ contrast). Orientation tuning is lost when the inhibition is below $\sim 3.5$ $\mathrm{nA}$ msec. For high levels of inhibition, orientation tuning at low contrasts appears broader because responses are close to the spontaneous activity level of the cells. The right axis and gray curve show the response to a preferred-orientation stimulus at $80 \%$ contrast. This response decreases sharply with inhibition and has a physiologically realistic level of $20-40 \mathrm{~Hz}$ for complex-cell inhibition at $\sim 4 \mathrm{nA}$ msec, a level that also produces contrast-invariant orientation tuning. The value used in the simulations was $4 \mathrm{nA}$ msec.

responses of the cells, it must interfere with the excitatory drive underlying responses. At the preferred orientation and spatial frequency, the antiphase simple-cell inhibition is significant only during temporal phases in which complex-cell inhibition already dominates excitation, and thus it has little effect. However, if the spatial frequency of the stimulating drifting grating does not match the spatial frequency preference of the cells (approximately given by the spatial frequency component of the Gabor filter; 0.8 cycles per degree), simple-cell inhibition can impact responses. For example, for a drifting grating stimulus of 0.4 cycles per degree, simple-cell inhibition rises (Fig. $4 b$ ) at times when complex cell inhibition and excitation are comparable (Fig. 4a), so that responses away from the preferred spatial frequency are somewhat suppressed by the addition of simple-cell inhibition (Fig. 4c,d). Thus, simple-cell inhibition serves to sharpen the spatial frequency tuning of the simple cells.

To study how this inhibition serves to sharpen the spatial frequency tuning, we examined the dependence of spatial frequency tuning on the strength of simple-cell inhibition. The $\mathrm{HWHH}$ of the spatial frequency tuning curve decreases with increasing simple-cell inhibitory strength until this strength reaches $\sim 8 \mathrm{nA} \mathrm{msec}$, the default level of simple-cell inhibitory strength used in our simulations with a mix of simple- and complex-cell inhibition, at which point the $\mathrm{HWHH}$ reaches a plateau level (Fig. 5). This sharpening is primarily attributable to an increase in the low spatial frequency cutoff of the cells, defined as the spatial frequency below the peak at which spike response is $50 \%$ of the peak response. There was no systematic change in the high spatial frequency cutoff with simple-cell inhibition (data not shown). Thus, there is a maximal level of simple-cell inhibition, beyond which increases do not further sharpen spatial frequency tuning, and this sharpening is primarily achieved by reducing the response to gratings of low spatial frequency. 
a Complex inh. only

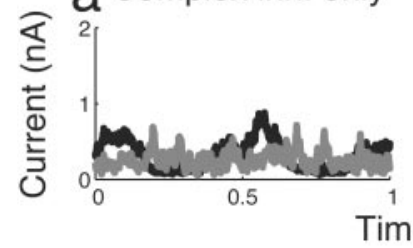

Time

C Exc. simple cells

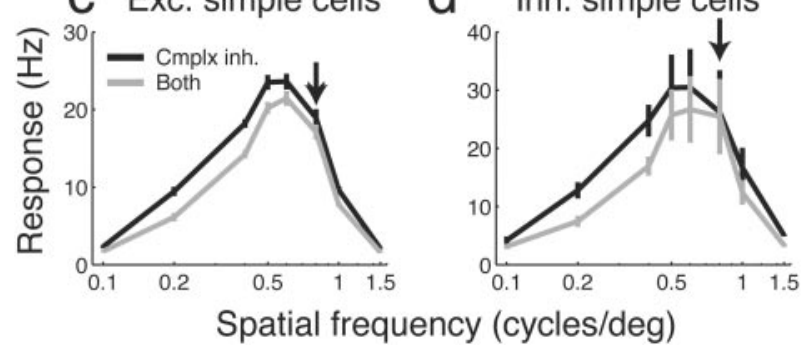

Figure 4. Spatial frequency tuning of simple cells is sharpened by simple-cell inhibition. $a, b$, Excitatory (black) and inhibitory (gray) synaptic currents versus time for a grating at a low spatial frequency ( 0.4 cycles per degree). $a$, Complex-cell inhibition only. $b$, Simple-cell and complex-cell inhibition. The modulated component of the inhibition interferes in time with the excitatory current, thus decreasing the firing rate of the cells. c, Response of the excitatory simple cells when stimulated with gratings of different spatial frequencies. Black, Complex cell inhibition only; gray, simple-cell and complex-cell inhibition. The arrow shows the frequency of the Gabor function defining simple-cell receptive fields. Adding simple-cell inhibition suppresses the response for frequencies from this Gabor frequency, thus sharpening the spatial frequency tuning of the simple cells. $d$, Response of inhibitory simple cells. Conventions are the same as those in $c$.

\section{Exc. cell responses}

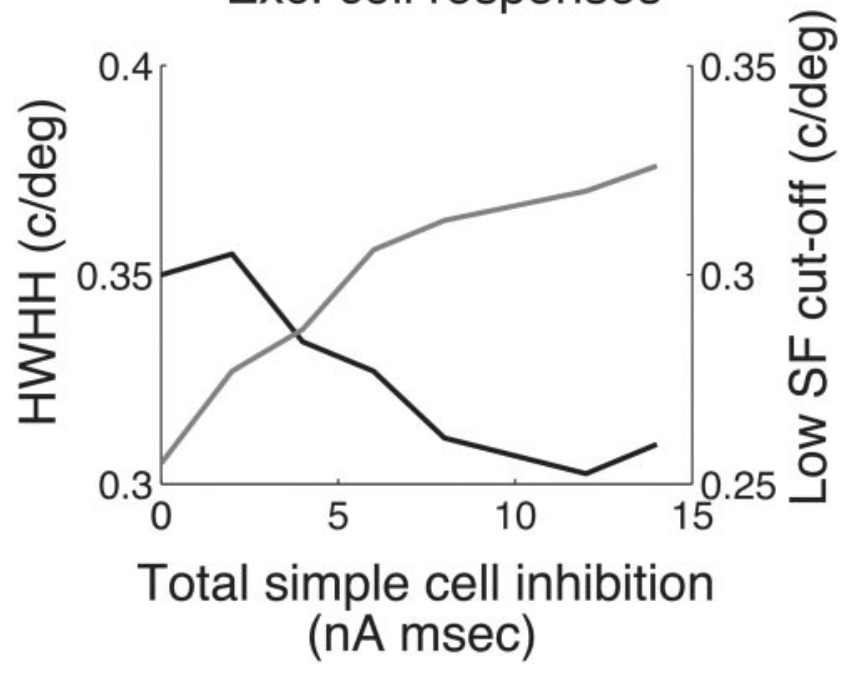

Figure 5. Spatial frequency tuning as a function of the simple-cell inhibition. The left axis and black curve show half-width at half-height of the spatial frequency tuning curve of the excitatory simple cells. This decreases with increasing simple-cell inhibition to a plateau level. The right axis and gray curve show the low spatial frequency cutoff of the cells. This increases similarly to the decrease in the half-width at half-height, indicating that it is the main contributor to the sharpening of the spatial frequency tuning.

\section{Temporal frequency tuning}

We have shown previously that the model with only simple-cell inhibition can explain the fact that cortical neurons have temporal frequency high-cutoffs at much lower frequencies than LGN cells (Krukowski and Miller, 2001). The explanation relied on the following two elements: NMDA receptor-mediated conductances (which we will refer to as NMDA) in synapses from LGN to
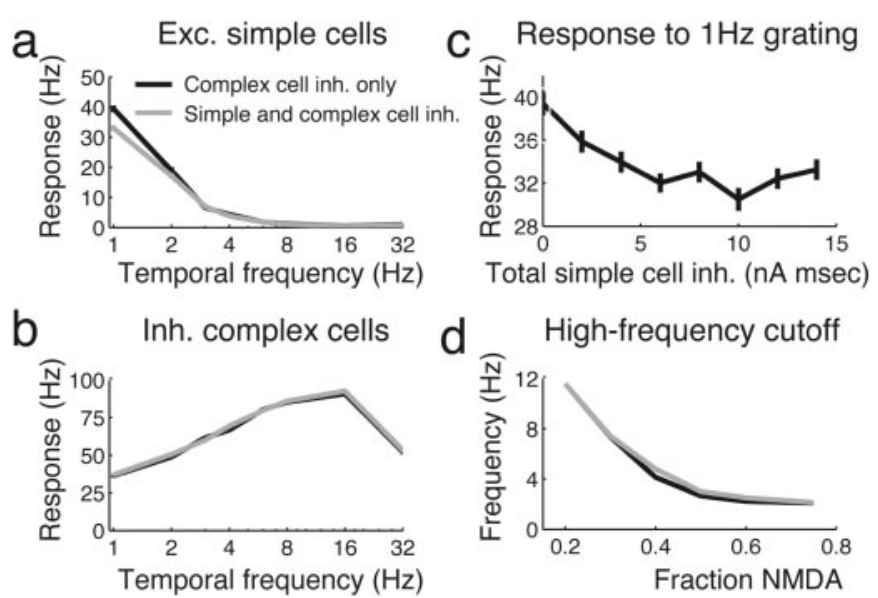

Figure 6. Temporal frequency tuning of simple cells is not dependent on simple-cell inhibition. $a$, Response of the excitatory simple cells when stimulating with gratings of increasing temporal frequency. Black, Complex-cell inhibition only; gray, both simple-cell and complexcell inhibition. Temporal frequency cutoff is similar in both cases. Temporal frequency cutoff for inhibitory simple cells is the same (data not shown). $b$, Temporal frequency tuning for the complex inhibitory cells follows the tuning of the LGN input. c, Response to stimulation with a drifting grating at $1 \mathrm{~Hz}$ for increasing simple-cell inhibition. The response decreases until simple-cell weights reach $\sim 6 \mathrm{nA} \mathrm{msec}$, and then it levels off. $d$, High temporal frequency cutoff as a function of the NMDA fraction in the thalamocortical synapses. The cutoff is similar both for complex cell inhibition only (black) and combined simple-cell and complex-cell inhibition (gray).

excitatory cells act as a low-pass filter, reducing the temporal modulation of the excitatory input at higher frequencies and thus primarily reducing this input to its mean; and the dominant inhibition prevents responses to the mean excitation. Note that this explanation requires that some inhibitory neurons respond to the high temporal frequencies that drive LGN cells.

This explanation of temporal frequency tuning also works with complex-cell inhibition, and is even more powerful in this case. Because complex-cell inhibition is not modulated at the opposite phase of the excitation, less demodulation of the excitation is required for the inhibition to dominate the excitation, and temporal frequency high-cutoffs occur at lower frequencies than in the previous model. Assuming that NMDA constitutes $75 \%$ of the current in LGN synapses onto excitatory cells, which corresponds to observations in rat thalamocortical slices (Crair and Malenka, 1995), the resulting temporal frequency tuning of excitatory simple cells shows little or no response above $4 \mathrm{~Hz}$ (Fig. $6 a)$. In contrast, the complex inhibitory cells have temporal frequency tuning that follows that of our model LGN input, cutting off above $16 \mathrm{~Hz}$ (Fig. 6b). Defining the high-frequency cutoff as the temporal frequency above the peak at which the mean spike response is reduced to $50 \%$ of the peak response, the cutoff of simple cells is $\sim 2 \mathrm{~Hz}$. This is low but still within the range of cells reported experimentally (Movshon et al., 1978; Freeman et al., 2002). Decreasing the fraction of NMDA in the thalamocortical synapses to the excitatory cells decreases the demodulation of the excitatory input at higher temporal frequencies and hence causes the high-frequency cutoff to increase (Fig. $6 d$ ). If the proportion of NMDA is halved from the amount we assumed, the cutoff is $\sim 6 \mathrm{~Hz}$, which is a representative experimental cutoff value for cortical cells (Ikeda and Wright, 1975; Movshon et al., 1978; Holub and Morton-Gibson, 1981; Saul and Humphrey, 1992b; DeAngelis et al., 1993; Freeman et al., 2002). In simulations without NMDA, we found that cortical temporal tuning closely follows LGN tuning (data not shown). 


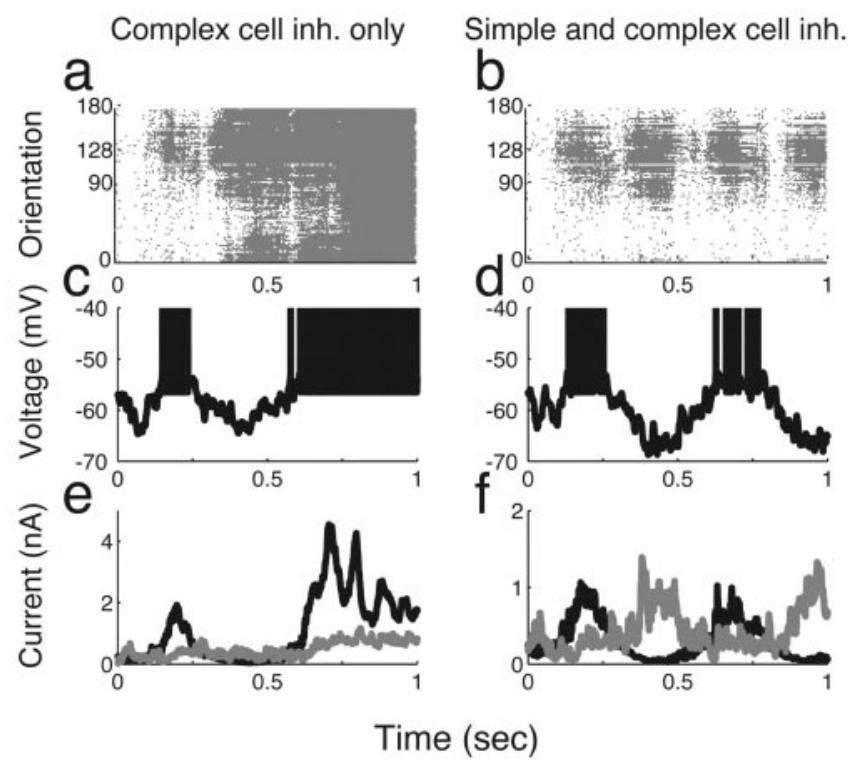

Figure 7. Simple-cell inhibition can stabilize otherwise unstable network. $a, c, e$, Complexcell inhibition only. $b, d$, $f$, Simple-cell and complex-cell inhibition. $a, b$, Raster plots of all excitatory cells arranged according to their preferred orientation. Although the activity of the network spreads to all orientations for complex-cell inhibition only, adding simple-cell inhibition can restrict the activity to cells only at the preferred orientation of the grating. c, Membrane potential.e, Synaptic current for a single cell. Black, Excitatory current; gray, inhibitory current. Excitatory synaptic current increases and is not shut off again. $d, f$, Same as $c$ and $e$ with the addition of simple-cell inhibition. The addition of antiphase-modulated inhibition is enough to shut off excitatory current.

The addition of simple-cell inhibition up to $\sim 6 \mathrm{nA}$ msec causes a decrease in the response to gratings at low temporal frequencies (Fig. 6c). Because the simple-cell inhibition does not affect the response at higher temporal frequencies, it does not have a significant effect on the temporal frequency cutoff (Fig. $6 d$ ).

Temporal frequency tuning of inhibitory simple cells in the model is primarily identical to that of excitatory simple cells (data not shown). This is easily understood because the inhibitory simple cells in the model receive the majority of their excitatory drive from excitatory simple cells, and their overall tuning follows that of this excitatory drive. We did not include NMDA in LGN synapses onto inhibitory cells; thus, the LGN-driven component of excitation does not demodulate with increasing temporal frequency and, hence, yields tuning like that of the LGN inputs, adding a small excitatory component at higher temporal frequencies to inhibitory simple-cell responses. Both factors, the relative strength of their feedback versus feedforward excitatory drive and the proportion of NMDA, if any, in their LGN synapses, shape the temporal frequency tuning of inhibitory simple cells. Because these are not well experimentally constrained, we cannot make strong predictions as to the exact temporal frequency tuning of the inhibitory simple cells other than to point out how it will be controlled by these two factors.

\section{Network stability}

The network including only simple-cell inhibition is stable for a fairly large parameter regime (Troyer et al., 1998). Here, we show that the network including only complex-cell inhibition is fragile and prone to at least one form of instability, and that simple-cell inhibition can help to expand the stable parameter regime.

If we increase all intracortical synaptic weights, both excitatory and inhibitory, by $20 \%$ in a network with only complex-cell
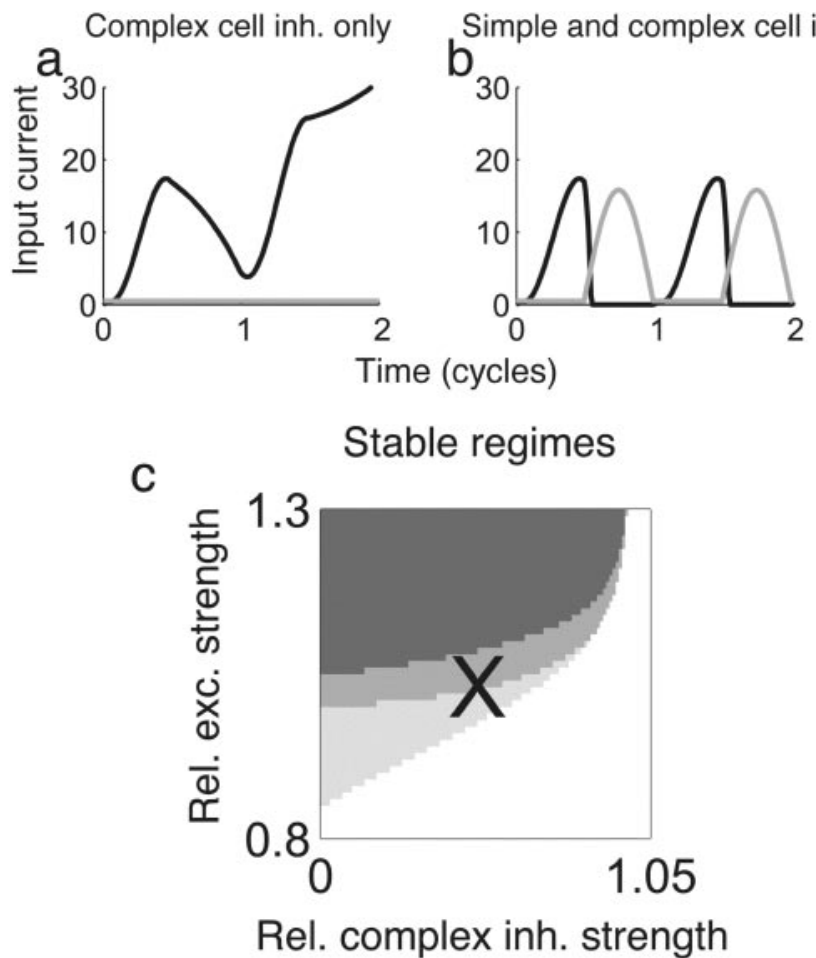

Figure 8. In a toy model, stable parameter regime is increased by simple-cell inhibition. $a, b$, Excitatory input current (black) and inhibitory input current (gray) to a cell. Although excitatory current can grow without bound with complex inhibition only, simple-cell inhibition resets the excitatory current on each cycle, thus stabilizing network activity. c, Stability of the response as a function of complex inhibitory strength, $C$, and excitatory strength, $w_{\text {ex }}$, for fixed simpleinhibition strength. White, Parameter regime in which responses to preferred orientation are too low $(<2)$; light gray, stable response for both types of inhibition; medium gray, uncontrolled response for complex inhibition only but stable for simple-plus complex inhibition; dark gray, unstable for both types of inhibition. Adding simple-cell inhibition significantly increases the stable parameter regime of the toy model. $X$ indicates the case shown in $a$ and $b . C=0.5$; $w_{\mathrm{ex}}=1.022$.

inhibition, a drifting grating of one orientation evokes tonic firing from cells preferring all orientations (Fig. 7a). The recurrent excitatory synaptic current builds over time, resulting in uncontrolled firing (Fig. $7 c, e$ ). Adding simple-cell inhibition restores the network to a stable firing state (Fig. $7 b, d, f$ ). The increased inhibitory synaptic current from the simple cells acts to reset the network during nonresponsive phases of the stimulus, shutting down overactive cells and stabilizing the network.

To explore the conditions for this stabilization effect to occur, we constructed a toy model of a simple cell receiving the following four input currents: a thalamocortical input modulated with time, a recurrent excitatory input proportional to the activity of the cell, a complex-cell inhibitory input constant with time, and an antiphase simple-cell inhibitory input modulated with time. The response of the cell, $r$, is the difference between its excitatory and inhibitory inputs, rectified over a threshold, $\theta$. For fixed threshold and simple-cell inhibitory strength, we can determine the stability of the model for a range of excitatory recurrent strengths and inhibitory complex strengths. By defining the stable regime as one in which the response of the cell is larger than a minimum response but does not grow indefinitely, we can compare the size of the stable regime both with and without simple-cell inhibition (Fig. 8c). For both scenarios, the minimum response is found for the same parameters, because simple-cell inhibition is out of phase with excitation. However, the size of the parameter regime in 
which the activity does not grow indefinitely is significantly increased when including antiphase simple-cell inhibition. For the fixed parameters used here, the ratio of the area of the two stable regimes is $\sim 2: 1$. The degree of this increase depends on the strength of the simple-cell inhibition, but even very weak simple-cell inhibition causes an increase in the area of the stable regime (data not shown). Thus, we can conclude qualitatively that simple-cell inhibition increases the size of the stable regime, although we cannot draw a parameter-free conclusion as to the size of this increase. Comparing the relative size of the inhibitory and excitatory traces in Figure $7 f$ to those in Figure $8 b$ indicates that the simple-cell inhibitory strength in the toy model, which achieves a 2:1 increase in stability, is comparable with the strength in the full model.

\section{Discussion}

We have shown that feedforward inhibition from complex inhibitory cells that are untuned for orientation, as observed by Hirsch et al. $(2000,2003)$ in cat V1 layer 4, can combine with feedforward excitation from LGN inputs to explain the sharp, contrastinvariant orientation tuning of layer 4 simple cells. Assuming that these inhibitory cells follow the LGN inputs in their temporal frequency tuning, and given NMDA receptor-mediated conductances in LGN synapses, this can also explain the low-pass temporal frequency tuning of simple cells. However, the parameter regime where this is achieved is restricted. Given complex cell inhibition, antiphase simple-cell inhibition acts to somewhat sharpen the spatial frequency tuning of simple cells, to reduce their responses to low temporal frequency stimuli, and to help stabilize the network, somewhat expanding the allowable parameter regime.

\section{Model predictions}

Predictions of the model include the following: (1) Simple cells receiving significant thalamic excitation should receive a comparable level of orientation-untuned inhibition, yielding detectable conductance changes in response to a stimulus oriented perpendicular to the preferred. Such conductance changes were seen in some but not all simple cells studied by Anderson et al. (2000a). Cells receiving little thalamic input could inherit their tuning from cells receiving such input and hence would not require such conductance changes. (2) Complex inhibitory cells should have temporal frequency tuning like that of the LGN inputs, responding to high temporal frequencies to which few other cortical cells respond. This gains some support from results in rabbit somatosensory (Swadlow, 1989, 1991) and motor (Swadlow, 1994) cortex that suspected interneurons (SINS) follow much higher temporal frequencies of peripheral stimulation than other cortical cells. (3) Thalamocortical synapses onto excitatory cells should include a significant NMDA receptor-mediated component. This agrees with slice studies of thalamocortical synapses (Crair and Malenka, 1995; Gil and Amitai, 1996) and with some (Miller et al., 1989) but not other (Fox et al., 1989) studies of V1 physiology.

In addition, assumptions as to circuit structure need testing. We assumed that simple inhibitory cells in layer 4 receive strong LGN input that is specifically arranged like that of other simple cells (Tanaka, 1983; Reid and Alonso, 1995; Alonso et al., 2001) and make connections that tend to be antiphase (Ferster, 1988; Hirsch et al., 1998; Anderson et al., 2000a), and that complex inhibitory cells in layer 4 receive strong LGN input that is nonspecific and project nonspecifically to other cortical cells.

\section{Complex-cell feedforward inhibition as a solution to the problem posed by the LGN inputs}

The problem posed by the LGN inputs to a simple cell is that the mean rate of LGN input grows with contrast at both nonpreferred orientations and high temporal frequencies, yet most excitatory simple cells do not respond to these stimuli. The solution we proposed is that broadly tuned feedforward inhibition cancels this mean input, allowing responses only to the peaks of temporally modulated excitatory input. This inhibition might arise from orientation-untuned complex cells (this study) or simple cells that respond to all orientations (previous studies). Because Hirsch et al. (2003) found that a minority of inhibitory simple cells responds strongly to all orientations (see Introduction), both types of inhibitory cells may actually contribute; we focused on a single type for simplicity.

We argue that a significant part of this inhibition must be feedforward for two reasons. First, in response to the positive pulse of LGN input evoked by transient nonpreferred stimuli such as a high-contrast flashed bar or grating of the null orientation of the cell, the inhibition must arrive in time to prevent spiking [see Gillespie et al. (2001) and Felsen et al. (2002) for evidence that many cat V1 cells do not respond to such stimuli]. The stimulus evokes a positive pulse of input because it excites some LGN inputs to the simple cell and inhibits others, and those that are excited can raise their firing rates much more strongly than those that are inhibited can lower theirs. Fast-spiking inhibitory cells have higher resistances and lower thresholds than excitatory cells (McCormick et al., 1985) and thus can respond very rapidly (e.g., within $0-1 \mathrm{msec}$ after thalamic action potentials reach cortex in rabbit somatosensory cortex) (Swadlow, 1995). Hence, these cells can spike in time to prevent spiking in excitatory cells (Somers et al., 1995). Consistent with this, shocks to LGN elicit in LGN-recipient cortical cells a short depolarization followed by, before spike threshold is reached, a massive hyperpolarization (Ferster and Jagadeesh, 1992) induced by inhibitory neuronal firing. Second, the required inhibition seems likely to be driven by LGN rather than cortical excitation, because it must be driven by stimuli that excite LGN cells but do not excite most cortical cells. However, the minority of excitatory simple cells that does respond to the stimulus (a very small minority in the case of high temporal frequency stimuli) (Freeman et al., 2002) might provide this excitatory drive for steady state rather than transient stimuli. The inhibitory cells may of course also receive excitation from cortical cells. We only argue that the LGN-driven component of inhibition seems necessary and is sufficient to shape simple-cell orientation and temporal frequency tuning.

The solution via complex-cell inhibition requires relatively fine tuning of overall complex inhibitory strength. However, no additional specificity of these connections is needed; it suffices that complex cells receive topographic but otherwise nonspecific LGN input and project nonspecifically to nearby cortical cells. Thus, homeostatic mechanisms that can control overall inhibitory strength (Turrigiano and Nelson, 2000) could suffice to guide development of this inhibition. Hebbian mechanisms can guide development of inhibitory and excitatory simple-cell connections (Kayser and Miller, 2002).

The inclusion of complex-cell inhibition is consistent with experiments suggesting a push-pull arrangement of excitation and inhibition onto simple cells. Dark elicits inhibition in the RF where light elicits excitation and vice versa (Ferster, 1988; Hirsch et al., 1998). This is consistent with inhibition that is antiphase to excitation but also with partly or entirely phase-nonspecific inhibition along with phase-specific excitation; excitation, when 
evoked, overwhelms inhibition, and otherwise inhibition is seen. In response to optimal drifting gratings, the evoked inhibitory conductance in simple cells shows both a mean, or DC component, and a temporal modulation that is nearly antiphase to that of excitatory conductance (Anderson et al., 2000a). This is consistent with a circuit containing only antiphase simple-cell inhibition, because factors that cause inhibitory simple-cell firing rates to increase from background more strongly than they decrease, such as excitatory feedback and the minimum firing rate of zero, induce a DC. However, it is also consistent with a combination of antiphase simple-cell inhibition and complex-cell inhibition.

The orientation tuning of inhibition to simple cells is strongly peaked at the preferred orientation, dropping to low values at the orthogonal orientation (Ferster, 1986; Anderson et al., 2000a; Martinez et al., 2002; but see Monier et al., 2003). This suggests that orientation-tuned simple-cell inhibition is much stronger than orientation-untuned complex-cell inhibition.

Alternative solutions to the problem posed by the LGN inputs With respect to orientation tuning, an alternative possible source of inhibition is cross-orientation inhibition (inhibition, in response to nonpreferred orientations, arising from more distant tuned neurons preferring those orientations). Such inhibition would have to be weak because inhibition driven by the cross orientation is typically weak in layer 4 (Ferster, 1986; Anderson et al., 2000a; Martinez et al., 2002). There is no need to invoke such inhibition, given the presence of untuned local inhibition (Hirsch et al., 2000, 2003). Such local inhibition can also explain temporal frequency tuning, which could not be explained by crossorientation inhibition.

Related proposals were made in a model of monkey V1 layer 4 (McLaughlin et al., 2000; Wielaard et al., 2001). In this model, all cortical cells, both excitatory and inhibitory, received simple-cell patterns of LGN input and nonspecific, inhibition-dominated input from other cortical cells, both excitatory and inhibitory, within a given radius. The result was that cells received phasenonspecific feedforward inhibition, similar to our complex cell model. However, the absence of a phase-specific inhibitory component is inconsistent with findings in cats that inhibitory conductance to a drifting bar or grating is temporally modulated, approximately antiphase to excitatory conductance (Ferster, 1986, 1988; Anderson et al., 2000a). Furthermore, this connectivity scheme predicts that cells in linear zones of the orientation map respond to all orientations, whereas cells near orientation pinwheels show sharp orientation tuning (but see Kang et al., 2003). This is incorrect in cats, in which pinwheel and linear zone cells show spiking orientation tuning of the same width (Maldonado et al., 1997; Schummers et al., 2002). Pinwheel cells show broader voltage orientation tuning than linear zone cells (Schummers et al., 2002); although it is unclear whether this holds in layer 4, this is suggestive of a distance-dependent component of connectivity that is excitation-dominated, rather than inhibition-dominated, which we neglected. Finally, this connectivity scheme predicts that simple cells showing sharp orientation tuning should receive approximately equal intracortical inhibition in response to stimuli of all orientations, whereas cat layer 4 simple cells have inhibitory tuning that is strongly peaked at the preferred orientation (Ferster, 1986; Anderson et al., 2000a; Martinez et al., 2002).

In some respects, synaptic depression acts as a high-pass filter (Abbott et al., 1997; Tsodyks and Markram, 1997) and thus might eliminate changes in the mean LGN input, leaving only temporal modulations of that input. This could reduce or eliminate the need for feedforward inhibition. Our explorations to date suggest that, although synaptic depression can reduce the stimulusinduced mean LGN input to a simple cell, it cannot eliminate it, except at the lowest temporal frequencies (1-2 Hz) with very strong depression ["train" parameters of Kayser et al. (2001) vs the weaker "pulse" parameters used here, which do not eliminate the untuned mean LGN input] (Fig. $2 b$ ). In the course of a previous study (Kayser et al., 2001), we found that even with strong (train) depression, inhibition was required to obtain contrastinvariant orientation tuning. Furthermore, including such strong depression tends to eliminate the differences between stimulus contrasts, so that after incorporating the contrast saturation of LGN responses (Sclar, 1987; Cheng et al., 1995), cortical cells tend to saturate at significantly lower contrasts than observed experimentally (Kayser et al., 2001).

Strong depression might render voltage responses to high temporal frequency stimuli small enough that an appropriate threshold could explain the high-frequency cutoff of cortical cells without requiring that such stimuli evoke inhibition. However, preliminary investigations suggest that, in this scenario, an appropriate threshold for high-contrast stimuli will unrealistically suppress responses to low-contrast stimuli.

\section{Inhibitory neurons in other systems and the function of simple inhibitory neurons}

Studies in a variety of cortical systems in rodents and rabbits have identified SINS in extracellular recordings and found that SINS are broadly tuned or untuned for the parameters for which other nearby cells are tuned (Swadlow and Weyand, 1987; Swadlow, 1988, 1989, 1990, 1991, 1994, 1995, 2003; Simons and Carvell, 1989; Miller et al., 2001; Bruno and Simons, 2002; Swadlow and Gusev, 2002). In particular, in rabbit V1, SINS are untuned for orientation and have mixed $\mathrm{ON}-\mathrm{OFF}$ receptive fields similar to the complex cells studied here, whereas most other cells are tuned (Swadlow, 1988). The basis of this, at least in rat S1 whisker barrels (layer 4), is that SINS unselectively pool large numbers of functionally diverse thalamic inputs, receiving input on average from $65 \%$ of the thalamic neurons representing the same whisker (Bruno and Simons, 2002; Swadlow and Gusev, 2002). The high probability ( $\geq 0.6$ ) of gap junction connections between nearby interneurons of a given physiological type, fast-spiking (FS) or low-threshold spiking (LTS) (Galarreta and Hestrin, 1999, 2001, 2002; Gibson et al., 1999), also suggests that rodent interneurons are functionally nonspecific. Note that the simple-complex interneuron distinction in cat V1 does not correspond to this FS-LTS distinction (Hirsch et al., 2000, 2003).

These unselective inhibitory neurons receiving unselective thalamic input seem analogous to the complex inhibitory neurons reported by Hirsch et al. (2000, 2003). In contrast, simple inhibitory neurons, which have equally selective orientation tuning and subregion structure as their excitatory neighbors, are likely to receive specifically arranged ON and OFF LGN inputs like other simple cells (Tanaka, 1983; Reid and Alonso, 1995). It seems unlikely that they could show extensive gap junction coupling without losing their phase specificity, because simple cells of all preferred spatial phases are likely to be present in a local region (DeAngelis et al., 1999). We suggest that the complex-cell interneurons correspond to the rodent and rabbit SINS, whereas simple-cell interneurons either correspond to an unreported type of interneuron in rodents and rabbits, or are an evolutionarily new type of interneuron not found in rodents and rabbits.

If simple-cell interneurons are evolutionarily new, the ques- 
tion arises what function they serve. The answers we found here, sharpening spatial frequency tuning, reducing low temporal frequency responses, and increasing network stability, are not large effects. The question remains open.

\section{Model homogeneity versus physiological heterogeneity}

In our model, all LGN cells have identical response properties, except for ON versus OFF structure and retinotopic position, and all cortical cells receive LGN inputs specified by an identical Gabor function, except for orientation, phase, and retinotopic position. In reality, there is much variability in LGN spatial (So and Shapley, 1981; Cheng et al., 1995) and temporal (Derrington and Fuchs, 1979; Lehmkuhle et al., 1980; Sclar, 1987; Saul and Humphrey, 1990; Hamamoto et al., 1994; Mukherjee and Kaplan, 1995; Freeman et al., 2002) response properties and in cortical Gabor filters (Jones and Palmer, 1987; DeAngelis et al., 1993, 1999) and temporal response properties (Ikeda and Wright, 1975; Movshon et al., 1978; Saul and Humphrey, 1992b; DeAngelis et al., 1993, 1999; Albrecht, 1995; Freeman et al., 2002). By ignoring this diversity, we are able to focus on basic principles: how feedforward inhibition can eliminate the orientationuntuned and high temporal frequency mean LGN input to yield sharp orientation tuning and, along with thalamocortical NMDA receptors, low-pass temporal frequency tuning.

These same principles would apply in the presence of response heterogeneity. However, heterogeneity might lessen the problem to be solved. For example, some simple cells respond to all orientations (Azouz et al., 1997), suggesting that they receive less feedforward inhibition relative to feedforward excitation (and perhaps less recurrent excitation to keep response strength in a reasonable range) or have more broadly tuned Gabor functions describing their LGN inputs. Simple cells with lower temporal frequency cutoffs might receive LGN inputs with lower cutoffs. Consistent with this, Alonso et al. (2001) found significant correlation between the temporal properties of a cortical cell and its LGN inputs. This could lessen the amount of NMDA or strength of inhibition needed to explain the discrepancy between LGN and cortical cell tuning. However, a significant discrepancy would almost certainly remain, given the large overall difference between LGN and cortical temporal tuning (Freeman et al., 2002). Variation in integration times of LGN inputs would cause dispersal in phase of LGN responses at higher temporal frequencies, yielding temporal demodulation of LGN input and thus reducing the required NMDA. However, one can estimate (see Materials and Methods) that this decrease in amplitude between 2 and $8 \mathrm{~Hz}$ should be $27 \%$ or less for the majority of V1 cells. In contrast, NMDA levels that mimic cortical tuning (one-half of our default level; see Results) yield 60\% diminution under comparable conditions (LGN firing rate amplitudes constant across frequency; no synaptic depression), suggesting significant NMDA would still be required. Diversity in cortical temporal tuning could be explained by inter-cell diversity in the tuning or the range of integration times of LGN inputs, in the degree of NMDA on thalamocortical synapses, and in the strength of feedforward inhibition received. In summary, the principles found here would not be undermined by considering heterogeneity, and conversely they suggest means by which heterogeneity might be achieved.

Thalamic-recipient simple cells receiving relatively little feedforward inhibition should both respond well to all orientations and have higher temporal frequency cutoffs than typical. Although each response property can have other causes, it would be intriguing to search for a correlation between these response properties in layer 4 cells.

\section{References}

Abbott LF, Varela JA, Sen K, Nelson SB (1997) Synaptic depression and cortical gain control. Science 275:220-224.

Ahmed B, Anderson JC, Martin KA, Nelson JC (1997) Map of the synapses onto layer 4 basket cells of the primary visual cortex of the cat. J Comp Neurol 380:230-242.

Albrecht DG (1995) Visual cortex neurons in monkey and cat: effect of contrast on the spatial and temporal phase transfer functions. Vis Neurosci 12:1191-1210.

Alonso JM, Usrey WM, Reid RC (1996) Precisely correlated firing in cells of the lateral geniculate nucleus. Nature 383:815-819.

Alonso JM, Usrey WM, Reid RC (2001) Rules of connectivity between geniculate cells and simple cells in cat primary visual cortex. J Neurosci 21:4002-4015.

Anderson JS, Carandini M, Ferster D (2000a) Orientation tuning of input conductance, excitation, and inhibition in cat primary visual cortex. J Neurophysiol 84:909-926.

Anderson JS, Lampl I, Gillespie D, Ferster D (2000b) The contribution of noise to contrast invariance of orientation tuning in cat visual cortex. Science 290:1968-1972.

Angulo MC, Rossier J, Audinat E (1999) Postsynaptic glutamate receptors and integrative properties of fast-spiking interneurons in the rat neocortex. J Neurophysiol 82:1295-1302.

Azouz R, Gray CM, Nowak LG, McCormick DA (1997) Physiological properties of inhibitory interneurons in cat striate cortex. Cereb Cortex 7:534-545

Brumberg JC, Pinto DJ, Simons DJ (1996) Spatial gradients and inhibitory summation in the rat whisker barrel system. J Neurophysiol 76:130-140.

Bruno R, Simons D (2002) Feedforward mechanisms of excitatory and inhibitory cortical receptive fields. J Neurosci 22:10966-10975.

Bullier J, Henry GH (1979) Laminar distribution of first-order neurons and afferent terminals in cat striate cortex. J Neurophysiol 42:1271-1281.

Cheng H, Chino YM, Smith III E, Hamamoto J, Yoshida K (1995) Transfer characteristics of lateral geniculate nucleus $\mathrm{X}$ neurons in the cat: effects of spatial frequency and contrast. J Neurophysiol 74:2548-2557.

Crair MC, Malenka RC (1995) A critical period for long-term potentiation at thalamocortical synapses. Nature 375:325-328.

DeAngelis GC, Ohzawa I, Freeman RD (1993) Spatiotemporal organization of simple-cell receptive fields in the cat's striate cortex. I. General characteristics and postnatal development. J Neurophysiol 69:1091-1117.

DeAngelis GC, Ghose GM, Ohzawa I, Freeman RD (1999) Functional micro-organization of primary visual cortex: receptive field analysis of nearby neurons. J Neurosci 19:4046-4064.

Derrington AM, Fuchs AF (1979) Spatial and temporal properties of X and Y cells in the cat lateral geniculate nucleus. J Physiol (Lond) 293:347-364.

Felsen G, Shen Y, Yao H, Spor G, Li C, Dan Y (2002) Dynamic modification of cortical orientation tuning mediated by recurrent connections. Neuron 36:945-954.

Ferster D (1986) Orientation selectivity of synaptic potentials in neurons of cat primary visual cortex. J Neurosci 6:1284-1301.

Ferster D (1988) Spatially opponent excitation and inhibition in simple cells of the cat visual cortex. J Neurosci 8:1172-1180.

Ferster D (1990a) X-and Y-mediated current sources in areas 17 and 18 of cat visual cortex. Vis Neurosci 4:135-145.

Ferster D (1990b) X- and Y-mediated synaptic potentials in neurons of areas 17 and 18 of cat visual cortex. Vis Neurosci 4:115-133.

Ferster D, Jagadeesh B (1992) EPSP-IPSP interactions in cat visual cortex studied with in vivo whole-cell patch recording. J Neurosci 12:1262-1274.

Ferster D, Miller KD (2000) Neural mechanisms of orientation selectivity in the visual cortex. Annu Rev Neurosci 23:441-471.

Ferster D, Chung S, Wheat H (1996) Orientation selectivity of thalamic input to simple cells of cat visual cortex. Nature 380:249-252.

Fox K, Sato H, Daw N (1989) The location and function of NMDA receptors in cat and kitten visual cortex. J Neurosci 9:2443-2454.

Freeman T, Durand S, Kiper D, Carandini M (2002) Suppression without inhibition in visual cortex. Neuron 35:759-771.

Gabbott PLA, Martin KAC, Whitteridge D (1988) Evidence for the connection between a clutch cell and a corticotectal neuron in area 17 of the cat's visual cortex. Proc R Soc Lond B Biol Sci 233:385-391. 
Galarreta M, Hestrin S (1999) A network of fast-spiking cells in the neocortex connected by electrical synapses. Nature 402:72-75.

Galarreta M, Hestrin S (2001) Electrical synapses between GABA-releasing interneurons. Nat Rev Neurosci 2:425-433.

Galarreta M, Hestrin S (2002) Electrical and chemical synapses among parvalbumin fast-spiking GABAergic interneurons in adult mouse neocortex. Proc Natl Acad Sci USA 99:12438-12443.

Gibson JR, Beierlein M, Connors BW (1999) Two networks of electrically coupled inhibitory neurons in neocortex. Nature 462:75-79.

Gil Z, Amitai Y (1996) Adult thalamocortical transmission involves both NMDA and non-NMDA receptors. J Neurophysiol 76:2547-2554.

Gilbert CD (1977) Laminar differences in receptive field properties of cells in cat primary visual cortex. J Physiol (Lond) 268:391-421.

Gilbert CD, Wiesel TN (1979) Morphology and intracortical projections of functionally characterised neurones in the cat visual cortex. Nature 280:120-125

Gillespie DC, Lampl I, Anderson JS, Ferster D (2001) Dynamics of the orientation-tuned membrane potential response in cat primary visual cortex. Nat Neurosci 4:1014-1019.

Gupta A, Wang Y, Markram H (2000) Organizing principles for a diversity of GABAergic interneurons and synapses in neocortex. Science 287:273-278.

Hamamoto J, Cheng H, Yoshida K, Smith III E, Chino YM (1994) Transfer characteristics of lateral geniculate nucleus $\mathrm{X}$ neurons in the cat: effects of temporal frequency. Exp Brain Res 98:191-199.

Hirsch JA, Alonso J-M, Reid RC, Martinez L (1998) Synaptic integration in striate cortical simple cells. J Neurosci 18:9517-9528.

Hirsch JA, Alonso J-M, Pillai C, Pierre C (2000) Simple and complex inhibitory cells in layer 4 of cat visual cortex. Soc Neurosci Abstr 26:1083.

Hirsch JA, Martinez LM, Piccai C, Alonso J-M, Wang Q, Sommer FT (2003) Functionally distinct inhibitory neurons at the first stage of visual cortical processing. Nat Neurosci, in press.

Holub RA, Morton-Gibson M (1981) Response of visual cortical neurons of the cat to moving sinusoidal gratings: response-contrast functions and spatiotemporal interactions. J Neurophysiol 46:1244-1259.

Hubel DH, Wiesel TN (1962) Receptive fields, binocular interaction and functional architecture in the cat's visual cortex. J Physiol (Lond) 160:106-154.

Ikeda H, Wright MJ (1975) Spatial and temporal properties of sustained and transient neurones in area 17 of the cat's visual cortex. Exp Brain Res 22:363-383.

Jones JP, Palmer LA (1987) The two-dimensional spatial structure of simple receptive fields in cat striate cortex. J Neurophysiol 58:1187-1211.

Kang K, Shelley M, Sompolinsky H (2003) Mexican hats and pinwheels in visual cortex. Proc Natl Acad Sci USA 100:2848-2853.

Kaplan E, Purpura K, Shapley RM (1987) Contrast affects the transmission of visual information through the mammalian lateral geniculate nucleus. J Physiol (Lond) 391:267-288.

Kayser AS, Miller KD (2002) Opponent inhibition: a developmental model of layer 4 of the neocortical circuit. Neuron 33:131-142.

Kayser AS, Priebe NJ, Miller KD (2001) Contrast-dependent nonlinearities arise locally in a model of contrast-invariant orientation tuning. J Neurophysiol 85:2130-2149.

Kisvarday ZF, Martin KAC, Whitteridge D, Somogyi P (1985) Synaptic connections of intracellularly filled clutch cells: a type of small basket cell in the visual cortex of the cat. J Comp Neurol 241:111-137.

Krukowski AE (2000) A model of cat primary visual cortex and its thalamic input. $\mathrm{PhD}$ thesis, University of California, San Francisco.

Krukowski AE, Miller KD (2001) Thalamocortical NMDA conductances and intracortical inhibition can explain cortical temporal tuning. Nat Neurosci 4:424-430.

Lauritzen TZ, Miller KD (2002) Contributions of simple- and complex-cell inhibition to simple cell responses in cat V1. Washington, DC: Society for Neuroscience Online 456.1.

Lauritzen TZ, Krukowski AE, Miller KD (2001) Local correlation-based circuitry can account for responses to multi-grating stimuli in a model of cat V1. J Neurophysiol 86:1803-1815.

Lehmkuhle S, Kratz KE, Mangel SC, Sherman SM (1980) Spatial and temporal sensitivity of X-and Y-cells in dorsal lateral geniculate nucleus of the cat. J Neurophysiol 43:520-541.

Ling DSF, Benardo LS (1995) Recruitment of $\mathrm{GABA}_{\mathrm{A}}$ inhibition in rat neo- cortex is limited and not NMDA dependent. J Neurophysiol 74:2329-2335.

Maldonado PE, Gödecke I, Gray CM, Bonhoeffer T (1997) Orientation selectivity in pinwheel centers in cat striate cortex. Science 276:1551-1555.

Martin KAC, Somogyi P, Whitteridge D (1983) Physiological and morphological properties of identified basket cells in the cat's visual cortex. Exp Brain Res 50:193-200.

Martinez L, Alonso J, Reid R, Hirsch J (2002) Laminar processing of stimulus orientation in cat visual cortex. J Physiol (Lond) 540:321-333.

McCormick DA, Connors BW, Lighthall JW, Prince DA (1985) Comparative electrophysiology of pyramidal and sparsely spiny stellate neurons of the neocortex. J Neurophysiol 54:782-805.

McLaughlin D, Shapley R, Shelley M, Wielaard DJ (2000) A neuronal network model of macaque primary visual cortex (V1): orientation selectivity and dynamics in the input layer $4 \mathrm{c} \alpha$. Proc Natl Acad Sci USA 97:8087-8092.

Miller KD, Chapman B, Stryker MP (1989) Visual responses in adult cat visual cortex depend on $N$-methyl-D-aspartate receptors. Proc Natl Acad Sci USA 86:5183-5187.

Miller KD, Simons DJ, Pinto DJ (2001) Processing in layer 4 of the neocortical circuit: new insights from visual and somatosensory cortex. Curr Opin Neurobiol 11:488-497.

Monier C, Chavane F, Baudot P, Graham L, Fregnac Y (2003) Orientation and direction selectivity of synaptic inputs in visual cortical neurons: a diversity of combinations produces spike tuning. Neuron 37:663-680.

Movshon JA, Thompson ID, Tolhurst DJ (1978) Spatial and temporal contrast sensitivity of neurones in areas 17 and 18 of the cat visual cortex. J Physiol (Lond) 283:101-120.

Mukherjee P, Kaplan E (1995) Dynamics of neurons in the cat lateral geniculate nucleus: in vivo electrophysiology and computational modeling. J Neurophysiol 74:1222-1243.

Peters A, Yilmaz E (1993) Neuronal organization in area-17 of cat visual cortex. Cereb Cortex 3:49-68.

Reid RC, Alonso JM (1995) Specificity of monosynaptic connections from thalamus to visual cortex. Nature 378:281-284.

Saul AB, Humphrey AL (1990) Spatial and temporal response properties of lagged and nonlagged cells in cat lateral geniculate nucleus. J Neurophysiol 64:206-224.

Saul AB, Humphrey AL (1992a) Evidence of input from lagged cells in the lateral geniculate nucleus to simple cells in cortical area 17 of the cat. J Neurophysiol 68:1190-1208.

Saul AB, Humphrey AL (1992b) Temporal frequency tuning of direction selectivity in cat visual cortex. Vis Neurosci 8:365-372.

Schummers J, Marino J, Sur M (2002) Synaptic integration by V1 neurons depends on location within the orientation map. Neuron 36:969-978.

Sclar G (1987) Expression of "retinal" contrast gain control by neurons of the cat's lateral geniculate nucleus. Exp Brain Res 66:589-596.

Sclar G, Freeman RD (1982) Orientation selectivity in the cat's striate cortex is invariant with stimulus contrast. Exp Brain Res 46:457-461.

Sherman SM (1985) Functional organization of the W-, X-, and Y-cell pathways in the cat: a review and hypothesis. Prog Psychobiol Physiol Psychol 11:233-314.

Simons DJ, Carvell GE (1989) Thalamocortical response transformation in the rat vibrissa/barrel system. J Neurophysiol 61:311-330.

Skottun BC, Bradley A, Sclar G, Ohzawa I, Freeman RD (1987) The effects of contrast on visual orientation and spatial frequency discrimination: a comparison of single cells and behavior. J Neurophysiol 57:773-786.

Skottun BC, De Valois RL, Grosof DH, Movshon JA, Albrecht DG, Bonds AB (1991) Classifying simple and complex cells on the basis of response modulation. Vision Res 38:1079-1086.

So YT, Shapley R (1981) Spatial tuning of cells in and around lateral geniculate nucleus of the cat: $\mathrm{X}$ and $\mathrm{Y}$ relay cells and perigeniculate interneurons. J Neurophysiol 45:107-120.

Somers D, Nelson SB, Sur M (1995) An emergent model of orientation selectivity in cat visual cortical simple cells. J Neurosci 15:5448-5465.

Swadlow H (2003) Fast-spike interneurons and feedforward inhibition in awake sensory neocortex. Cereb Cortex 13:25-32.

Swadlow HA (1988) Efferent neurons and suspected interneurons in binocular visual cortex of the awake rabbit: receptive fields and binocular properties. J Neurophysiol 59:1162-1187.

Swadlow HA (1989) Efferent neurons and suspected interneurons in S-1 
vibrissa cortex of the awake rabbit: receptive fields and axonal properties. J Neurophysiol 62:288-308.

Swadlow HA (1990) Efferent neurons and suspected interneurons in S-1 forelimb representation of the awake rabbit: receptive fields and axonal properties. J Neurophysiol 63:1477-1498.

Swadlow HA (1991) Efferent neurons and suspected interneurons in second somatosensory cortex of the awake rabbit: receptive fields and axonal properties. J Neurophysiol 66:1392-1409.

Swadlow HA (1994) Efferent neurons and suspected interneurons in motor cortex of the awake rabbit: axonal properties, sensory receptive fields, and subthreshold synaptic inputs. J Neurophysiol 71:437-453.

Swadlow HA (1995) Influence of VPM thalamic afferents on putative inhibitory interneurons in S1 of the awake rabbit: evidence from crosscorrelation, microstimulation and latencies to peripheral sensory stimulation. J Neurophysiol 73:1584-1599.

Swadlow H, Gusev A (2002) Receptive-field construction in cortical inhibitory interneurons. Nat Neurosci 5:403-404.

Swadlow HA, Weyand TG (1987) Corticogeniculate neurons, corticotectal neurons, and suspected interneurons in visual cortex of awake rabbits: receptive-field properties, axonal properties, and effects of EEG arousal. J Neurophysiol 57:977-1001.

Tamas G, Buhl EH, Somogyi P (1997) Massive autaptic self-innervation of GABAergic neurons in cat visual cortex. J Neurosci 17:6352-6364.
Tamas G, Somogyi P, Buhl EH (1998) Differentially interconnected networks of GABAergic interneurons in the visual cortex of the cat. J Neurosci 18:4255-4270.

Tanaka K (1983) Cross-correlation analysis of geniculostriate neuronal relationships in cats. J Neurophysiol 49:1303-1318.

Troyer TW, Krukowski AE, Priebe NJ, Miller KD (1998) Contrast-invariant orientation tuning in cat visual cortex: feedforward tuning and correlation-based intracortical connectivity. J Neurosci 18:5908-5927.

Troyer TW, Krukowski AE, Miller KD (2002) LGN input to simple cells and contrast-invariant orientation tuning: an analysis. J Neurophysiol 87:2741-2752.

Tsodyks MV, Markram H (1997) The neural code between neocortical pyramidal neurons depends on neurotransmitter release probability. Proc Natl Acad Sci USA 94:719-723.

Turrigiano GG, Nelson SB (2000) Hebb and homeostasis in neuronal plasticity. Curr Opin Neurobiol 10:358-364.

Wielaard DJ, Shelley M, McLaughlin D, Shapley R (2001) How simple cells are made in a nonlinear network model of the visual cortex. J Neurosci 21:5203-5211.

Wörgötter F, Koch C (1991) A detailed model of the primary visual pathway in the cat: comparison of afferent excitatory and intracortical inhibitory connection schemes for orientation selectivity. J Neurosci 11:1959-1979. 